\title{
FROM PHILOSOPHY TO MATHEMATICS TO BIOLOGY ${ }^{1}$
}

\author{
BY WALTER ROSENBLITH AND JEROME WIESNER
}

Two months before his death, in a ceremony at the White House, Norbert Wiener was awarded the National Medal of Science. The citation by President Johnson said: " . . . for marvelously versatile contributions, profoundly original, ranging within pure and applied mathematics, and penetrating boldly into the engineering and biological sciences."

Our assignment here is twofold: we want to explore how Wiener came to penetrate into biology, a field into which few real mathematicians had strayed before him; we should also like to assess, no matter how incompletely, the imprint that Wiener has left upon the sciences of Life and Man.

From his early youth Wiener, the prodigy, acquired intensive experience in the manipulation of both mathematical and linguistic symbols; but his career choice seemed initially little related to these skills. Perhaps in part due to his father's acquaintance with Walter B. Cannon, Norbert seemed sufficiently interested in biology to become a graduate student in zoology at Harvard University, after he had graduated at the age of 14 from Tufts College. But, in spite of his interest in the subject matter, Norbert had neither the manual skill nor the patience to do well in the graduate courses in biology of that era. In one of his autobiographical books Wiener commented on the contrast between his quick insight into ideas and his extreme lack of manual dexterity as follows:

"This impatience was largely the result of a combination of my mental quickness and physical slowness. I would see the end to be accomplished long before I could labor through the manipulative stages that were to bring me there. When scientific work consists in meticulously careful and precise manipulation which is always to be accompanied by a neat record of progress, both written and graphical, impatience is a real handicap. How much of a handicap this syndrome of clumsiness was I could not know until I had tried. I had moved into biology, not because it corresponded with what I knew I could do, but because it corresponded with what I wanted to do.

"It was inevitable that those about me discouraged me from further work in zoology and all other sciences of experiment and ob-

1 Reprinted with permission of the authors and publisher from The Journal of Nervous and Mental Disease, Vol. 140, No. 1, Copyright (c) 1965, The Williams \& Wilkins Company. 
servation. Nevertheless, I have subsequently done effective work together with physiologists and other laboratory scientists who are better experimenters than I, and I have made some definite contributions to modern physiological work."

After a short period as a "philosopher despite himself," Wiener found his way into mathematics via a doctoral dissertation in the area of Russellian logic, and a few "Wander"-semesters at Cambridge (on the Cam) and Göttingen. The involvement of America in World War I brought Norbert Wiener to the Aberdeen Proving Grounds and involved him in the computation of ballistic tables. After a short and not too happy interlude as a journalist, Wiener joined the Massachusetts Institute of Technology Mathematics Department in 1919. Although during the next 45 years Wiener remained a productive member of this Department, he had an important influence in many other departments of the Institute as well. Few are the fields of science, engineering, social science or even humanistic scholarship which Wiener's thoughts failed to stir up, of ten in a rather unorthodox manner. Wiener's presence at M.I.T. spans the period during which the Institute transformed itself from a technical school into a university of a novel type, one "polarized around science," and his intellectual virtuosity, curiosity and integrity contributed importantly to that transition.

When Wiener came to M.I.T., the Mathematics Department was predominantly a service department concerned with preparing students for engineering careers. In a manner which more pure mathematicians in the United States could emulate, Wiener did not hesitate to become interested in the problems of his engineering colleagues. When many years later the great English mathematician, Hardy, claimed that Wiener's engineering terminology was mere camouflage, he misunderstood both Wiener's motivations and sense of social responsibility. Even the purest of mathematics can be a potent tool in very practical pursuits, and Wiener felt that mathematicians, to be effective, need to realize that their labors are changing the nature of society.

Most of Wiener's later mathematical work stemmed from his early interest in the study of irregularities and in his attempts to give meaningful mathematical descriptions of such irregularities, no matter where in nature they occur. His study of Brownian motion led him to study forms of harmonic analysis more general than the classical Fourier series and the Fourier integral. He developed both auto- and cross-correlation analysis and related them to the established forms of spectral analysis. 
Under Karl T. Compton's presidency of M.I.T., the Departments of Physics, Chemistry and Mathematics ceased being merely service departments and became the nucleus of a School of Science with increased commitment to what is today called Basic Research. But this enhanced status of mathematicians and of mathematical research did not lead Wiener to loosen his ties with his colleagues in the School of Engineering. On the contrary, during the 1930s, Vannevar Bush and several younger faculty members from M.I.T.'s Electrical Engineering Department interacted with Wiener in ways that came to affect the future of computer and communications engineering significantly, particularly through the use of sophisticated mathematical techniques.

Bush was beginning to overcome the technical obstacles that stood in the way of the construction of the differential analyzer, the preWorld War II forerunner of modern high-speed computing machinery. Wiener's close contact with this program and his joint work with Y. W. Lee on the design of electric circuits, led him to consider, most of ten in the abstract, the potentialities of the computers of the future and to search for criteria and concepts that would make it possible to separate message from adventitious noise. This was also the period during which Arturo Rosenblueth ${ }^{2}$ and Norbert Wiener examined closely -in a series of monthly discussion meetings-how the scientific method was being applied in a variety of fields.

During World War II Norbert Wiener worked on the design of fire control apparatus for anti-aircraft guns. In some sense this problem seemed to be tailor-made for him since it permitted him to pull together many of his previous interests: Wiener saw with great clarity the close relation between the statistical study of time series and the formulation of the basic task of communication engineering, namely the transmission of messages. For a message to be transmitted there must be a repertory or ensemble of possible messages and a way of assessing the probability of these messages. These topics when joined to the problems of filtering and prediction from existing time series comprise the substance of a book that Wiener wrote under the title of Extrapolation, interpolation and smoothing of stationary time series (with engineering applications). (During the war it was known by the more picturesque title of the "Yellow Peril"-the cover contributed the adjective.)

The study of fire-control problems led Wiener, for the first time, to

2Arturo Rosenblueth, at that time at Harvard Medical School, was the brilliant associate of Walter B. Cannon whose statement of the body's regulatory and stabilizing mechanisms represents one of the high points of classical physiology. 
deal directly with man in his coupling to a machine. Human sensory and motor abilities were involved in tracking behavior. The way man corrects for errors led to a general consideration of feedback mechanisms in stabilizing performance and of the particular pathology known as "hunting" in the presence of overapplication of feedback.

The type of analysis Wiener and his co-workers used was not too different in inspiration from the homeostatic, error-correcting mechanisms Cannon had dealt with, both conceptually and experimentally. Wiener and his engineering associate, Bigelow, therefore quite naturally consulted with Arturo Rosenblueth on "intention tremors" as the human pathological symptom that was most closely akin to the pathology encountered in servomechanisms. From this collaboration resulted the famous manifesto, "Behavior, Purpose and Teleology" [127]. ${ }^{3}$

Wiener emerged from this wartime work with a conviction that communications engineering, the behavior of servomechanisms, of computing machines and of the nervous system, could all be regarded from a unified overall viewpoint. Drawn by his enthusiasm, people from these disciplines and fields gathered around Wiener in Princeton in a meeting that foreshadowed the famous Macy Foundation series of conferences on Cybernetics.

These conferences, which were the prototype of the many multidisciplinary symposia that followed in the next two decades, subjected the fields that came to be known as sciences of communication to a searching examination. To Wiener and many of his colleagues, communication was clearly the cement of the nervous system, of society, of any complexly organized structure. There was less than unanimity among them and the scientific community at large as to whether cybernetics was a unifying science, a common basis for thought, a convenient common language for functionally related problems, a set of analogies or a program. Many sensational, sciencefictionish tales have been written and told under the cybernetic label (not by Wiener who when writing science fiction stories labeled them accordingly) but of ten by people of whom he was not as critical as he was of his closer colleagues.

The question has of ten been asked what specifically has Wiener (or cybernetics) contributed to fields other than mathematics. In the area of engineering there can be no doubt that his lifelong association with colleagues and problems has left a profound mark upon the way

3 The bold-faced numbers in brackets refer to the numbered references in the Bibliography of Norbert Wiener. 
much of engineering is practiced, conceptualized and taught. When it comes to the biological sciences, it is much harder to identify discrete contributions that he has made or problems that he has "solved." Since neither of us was trained in this area of science, we feel compelled to be cautious. But it seems that the work Wiener did (mainly with Rosenblueth) and especially the work he stimulated on such topics as biological regulation, characterization of the electroencephalogram as a time series, prosthetic devices, and much else has been of real substance and significance.

We had the good fortune to belong to the post-World War II Wiener Supper Seminar, we were his colleagues on the M.I.T. faculty, and saw at first hand his influence pervade the Institute and, in particular, the Research Laboratory of Electronics. We can offer personal testimony to the quasi-generality of his own remarks on his cooperation with the outstanding British mathematician Paley [92]; he wrote, "My role was primarily that of suggesting problems and the broad lines on which they might be attacked, and it was generally left to Paley to draw the strings tight." We, too, felt enriched by the problems he suggested and by the excitement he generated by his views of what needed to be done.

In areas in which Wiener's intuition was less educated than in engineering, he was of ten impatient with experimental details; for example, he seemed sometimes unwilling to learn that the brain did not behave the way he expected it to. Yet even those who have been most critical of his interpretation of data and his speculations can not fail to pay homage to the seminal influence he has exercised by acquainting many a scientist with a different kind of potentially relevant concepts and mathematical and engineering techniques. $\mathrm{He}$ had relatively little contact with the spectacular progress in molecular biology which took place after Cybernetics [138] had been written. This is a pity; for these challenging problems of the flow of intra- and inter-cellular information might have benefitted from an attack by his fertile intellect. He might have found here a still deeper understanding of the logical processes that are at work in living systems, whose nature so intrigued him.

Wiener solved neither all the problems of the brain nor those of the communication sciences; but he articulated them and gave many scientists a new way of looking at some of the most puzzling questions.

Our country was indeed fortunate to have had the complementary influences of Wiener, Von Neumann and Shannon at work in the immediate postwar period when our educational institutions went through a great expansion in research and graduate study. It was 
under the auspices of this Zeitgeist that young people from such different fields as neurophysiology, experimental psychology, linguistics and communications engineering started to learn and integrate into their professional lives the kinds of mathematical skills that their elders had just barely become familiar with under the name of cybernetics.

Wiener has left an enduring monument, for in a sense many a young, tough-minded scientist and engineer from these fields is entitled to call himself today a "cyberneticien malgré lui."

MASSAChusetrs Institute of Technology

(RESEARCH LABORATORY OF ElECtronics) 